\title{
Methods to collect Anopheles mosquitoes and evaluate malaria transmission: A comparative study in two villages in Senegal
}

\author{
Mamadou O Ndiath ${ }^{1 *}$, Catherine Mazenot ${ }^{1}$, Ablaye Gaye ${ }^{1,2}$, Lassana Konate ${ }^{2}$, Charles Bouganali , Ousmane Faye ${ }^{2}$, \\ Cheikh Sokhna ${ }^{1}$ and Jean-Francois Trape
}

\begin{abstract}
Background: Various methods have been studied as replacement of human landing catches (HLC) for mosquito sampling in entomological studies on malaria transmission. Conflicting results have been obtained in comparing relative efficiency of alternative methods, according to the area, the species present and their density. The aim of this study was to compare the number and characteristics of mosquitoes sampled in two areas of Senegal by three different methods: HLC, light traps adjacent to an occupied bed net (LT/N), pyrethrum spray catches (PSC).
\end{abstract}

Methods: Collections were performed in two villages: Dielmo (Soudan savanna) and Bandafassi (Soudan Guinean savanna), two or three nights per month for a 4-5 months period during the maximal transmission season in 20012002. Species were identified and Plasmodium infection determined by ELISA. The specific composition, circumsporozoite protein rate and entomological inoculation rate were calculated.

Results: The diversity of mosquito species captured was maximal with LT/N, minimal with PSC. The mean number of anopheles captures each night was significantly different according to the method used and the species. PSC displayed a significantly lower anopheles density. HLC was the most efficient sampling method when Anopheles gambiae was the main vector (in Bandafassi); LT/N when it was Anopheles funestus (in Dielmo). A significant correlation was found between HLC and LT/M but correlation parameters were different according to the species. Circumsporozoite protein rates were not significantly different between methods or species. The entomological inoculation rate varied along with vector density and thus with methods and species.

Conclusions: The choice of sampling method influenced entomological data recorded. Therefore, the sampling technique has to be chosen according to the vector studied and the aim of the study. Only HLC must be considered as the reference method, but in some conditions LT/N can be used as an alternative method.

\section{Background}

In order to measure malaria transmission, a good knowledge about its vectors is required. To achieve this goal, entomological studies with Anopheles collection are essential [1]. The choice of the method depends on the objectives of the study, the environment and the available means [2].

\footnotetext{
* Correspondence: ousmane.ndiatt@ird.fr

'Institut de Recherche pour le Développement, UMR 198 URMITE Campus international de Hann, IRD BP 1386 CP 18524 Dakar, Sénégal

Full list of author information is available at the end of the article
}

Human landing catch (HLC) is the most frequently used and considered as the reference method. It allows sampling mosquitoes that are aggressive against human, either endophagous or exophagous. It is the most reliable measure of human-vector contact for evaluating malaria transmission. On the other hand, it raises the ethical question of potential risk for collectors that are submitted to mosquito bite susceptible to transmit various pathogens. Results depend on collectors skills and on the attraction he/she exerts on mosquitoes. Several alternative sampling methods have been developed: use of various traps, light traps (CDC miniature light trap)

\section{Biomed Central}

(c) 2011 Ndiath et al; licensee BioMed Central Ltd. This is an Open Access article distributed under the terms of the Creative Commons Attribution License (http://creativecommons.org/licenses/by/2.0), which permits unrestricted use, distribution, and reproduction in any medium, provided the original work is properly cited. 
[3] with or without a person sleeping under a net, $\mathrm{CO}_{2}$ [4] or odour-baited traps (OBET) [5], exposure free bednet traps (Mbita) [6] and indoor resting catches by aspiration or spraying. Because they select only a fraction of the global anopheles population, each method is subjected to bias and shortcomings and, therefore, influences the results [7]. Specimens sampled by pyrethrum spray catches (PSC) are mostly fed females resting indoor in the morning. The use of traps, as the CDC Light Trap, associated with a person sleeping under a net $(\mathrm{LT} / \mathrm{N})$ should theoretically allows sampling the anthropophilic and endophagous specimens that are searched. However, the presence of light attracts other species that are not anthropophilic. Collections with LT/ $\mathrm{N}$ should allow a good standardization.

Malaria epidemiologic studies are currently performed in Dielmo and Bandafassi, two Senegalese villages. In these two sites, different vector species are present $[8,9]$. The aim of this study was to evaluate relative efficacy of three collection methods: Light traps associated with a person sleeping under a net $(\mathrm{LT} / \mathrm{N})$, pyrethrum spray catches (PSC) and Human Landing Catches (HLC).

\section{Methods}

\section{Study area}

The village of Dielmo $\left(13^{\circ} 45^{\prime} \mathrm{N}, 16^{\circ} 25^{\prime} \mathrm{W}\right)$ is situated $280 \mathrm{~km}$ south-east from Dakar, near the Gambian border. Rainfalls (around $630 \mathrm{~mm}$ /year) occur between June and October. A small permanent stream situated near the village constitutes a site for Anopheles larval growth. Malaria is holoendemic and transmission occurs all the year round [10]. The village of Bandafassi $\left(12^{\circ} 33^{\prime} \mathrm{N}, 12^{\circ}\right.$ $17^{\prime} \mathrm{W}$ ) is situated $730 \mathrm{~km}$ south-east from Dakar. Rainfalls (1,500 mm/year) occur between May and November. Malaria is hyperendemic with long seasonal transmission [11].

\section{Sampling methods}

Collections were performed three times per month from October 2001 to January 2002 in Dielmo and twice monthly from July to October 2002 in Bandafassi. Night catches were performed simultaneously indoor between $7 \mathrm{PM}$ and 7 AM by HLC and LT/N methods. HLC were performed by two trained collectors (adult male volunteers) working alternatively for one hour and resting for one hour. Village nurses provided medical supervision of collectors. LT/N catches were performed using a CDC mini light trap [3] placed adjacently and above an occupied bed net. PSCs were performed at 7 AM by spraying Deltamethrin (Yotox ${ }^{\circledR}$ ) for 30-45 seconds in the room. After 10 minutes, dead and immobilized mosquitoes were collected. Two sites per villages were randomly selected. In each site, three rooms were randomly chosen within a 15-m distance. Each night, a different sampling method was tested in each room.

\section{Mosquito analysis}

After collection, specimens were brought back to the field laboratory and Anopheles morphologically identified according to Gillies and DeMeillon keys [12]. Females were counted and stored for further analysis. The expression of circumsporozoite protein (CSP) was assessed by ELISA in the laboratory in Dakar [13].

\section{Data analyses}

For each method, the number of species, human biting rate (HBR) or Anopheles density (number of Anopheles per person and per night) and CSP rate were calculated. The entomological inoculation rate (EIR) was defined as the number of Anopheles person and per night multiplied by the CSP rate and expressed in number of infected bite per person per night. The mean number of mosquitoes collected per night was compared by ANOVA with following factors (village, method and species) after log +1 normalization (Shapiro-Wilk test) with post hoc Bonferroni test. CSP rates were compared using Pearson or Fisher $\mathrm{Chi}^{2}$. The correlation between LT/N and HLC was studied with Spearman test.

\section{Ethical approval}

Free and informed consent was obtained from collectors performing HLC and LT/N. Permission was sought from inhabitants to perform collections in their rooms. Community consent had been obtained beforehand in both villages. This study was approved by the Ethical National Comity of Senegal.

\section{Results}

\section{Anopheles density and diversity}

In Dielmo, LT/ $\mathrm{N}$ was the method that allowed collecting the highest variety and quantity of Anopheles (1,164 specimens belonging to five different species). HLC method gave lower results with 897 specimens belonging to three different species. Only 439 specimens belonging to two different species were collected by PSC.

In Bandafassi, similar results were obtained with nine different species collected by LT/N, 6 by HLC. However, the number of specimens collected was higher with HLC (1841 vs. 1061 with LT/N). For variety (4 different species) as well as for quantity (444) PSC was the method that displayed the lowest result (Table 1).

The mean number of Anopheles collected per person and per night is represented on Figure 1. Analysis demonstrated a significant difference according to species $(\mathrm{F}=32.95, \mathrm{p}<0.0001)$. In Dielmo, significantly more Anopheles funestus than Anopheles gambiae were 
Table 1 Number of Anopheles collected in Dielmo and in Bandafassi according to species and method used (HLC: human landing catches, PSC: pyrethrum spray catches, LT/N Light trap associated with a person sleeping under a net)

\begin{tabular}{lcccccc}
\hline & \multicolumn{3}{c}{ DIELMO } & \multicolumn{3}{c}{ BANDAFASSI } \\
\cline { 2 - 7 } & HLC & PSC & LT/N & HLC & PSC & LT/N \\
\hline An. gambiae s.l. & 219 & 164 & 169 & 1555 & 391 & 953 \\
An. funestus & 676 & 275 & 983 & 56 & 33 & 54 \\
An. nili & - & - & - & 223 & 14 & 30 \\
An. ziemanni & - & - & 7 & 1 & - & 11 \\
An. coustani & - & - & - & 3 & - & 2 \\
An. domicola & - & - & - & 3 & - & 3 \\
An. pharoensis & 2 & - & 1 & - & - & 5 \\
An. rufipes & - & - & 4 & - & 6 & 2 \\
An. paludis & - & - & - & - & - & 1 \\
\hline Total & 897 & 439 & 1164 & 1841 & 444 & 1061 \\
\hline
\end{tabular}

collected ( $\mathrm{p}<0.0001$, Bonferroni test). In Bandafassi, An. gambiae was the most encountered species ( $\mathrm{p}<$ 0.0001, Bonferroni test). A significant difference was demonstrated between methods $(\mathrm{F}=14.19, \mathrm{p}<0.0001)$ with HLC being significantly more efficient than PSC $(p=0.005$, Bonferroni test). No significant difference was observed between villages $(\mathrm{F}=0.12, \mathrm{p}=0.7$ ); on the other hand, a strong interaction was identified between village and species $(\mathrm{F}=139.72, \mathrm{p}<0.0001)$. For An. gambiae the relative efficiency of LT/N using HLC as reference was 0.6. For An. funestus it was 1.4.

\section{CSP rates}

The number of CSP positive mosquitoes and CSP rates are presented in Table 2. Infection rates were similar for all species when analysed in Dielmo (Fisher exact $\mathrm{p}=0.5$ ) or in Bandafassi (Fisher exact $p=0.28$ ). No significant difference could be identified between methods in Dielmo and in Bandafassi (Pearson $\mathrm{Chi}^{2}$ respectively 0.7, $\mathrm{p}=0.7$ and $0.6, p=0.8)$. CSP rate, calculated with pooled data from the three methods and species, was 3.0\% in Dielmo and $4.1 \%$ in Bandafassi.

\section{Transmission}

EIR calculated in the two villages according to the method used are represented on Figure 2. EIR measured with PSC was lower than those obtained with the other methods. EIR obtained with HLC was higher than LT/N in Bandafassi, where transmission is mainly due to $A n$. gambiae. In Dielmo, where transmission is mainly due to An. funestus, EIR obtained by LT/N was higher.

\section{Correlations between the two most efficient methods}

Since LT/N displayed the nearest results to HLC, the correlation between those two methods was studied (Figure 3). A

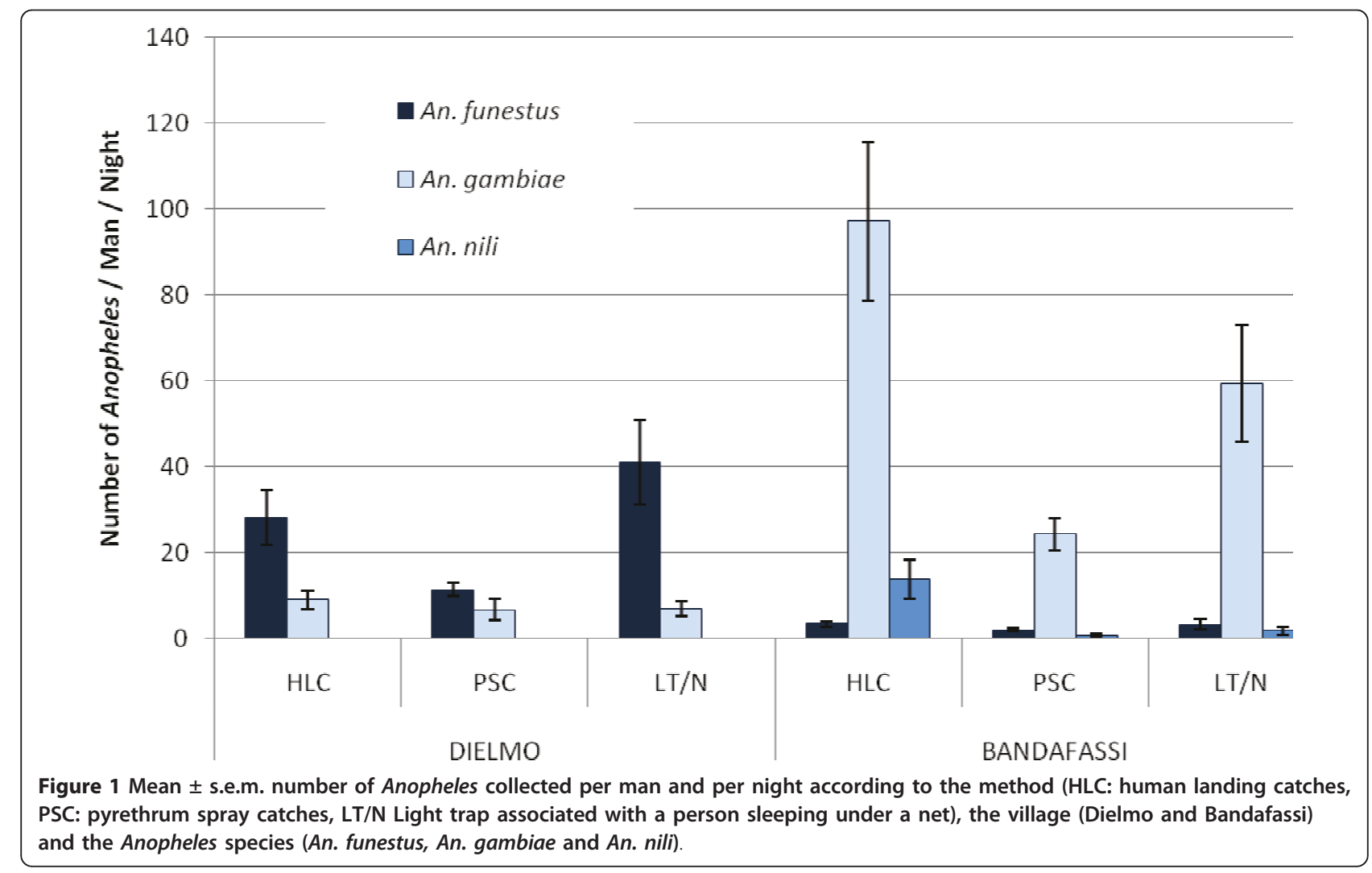


Table 2 Number of circumsporozoite protein (CSP) positive mosquito and corresponding CSP rate (\%) according to the method (HLC: human landing catches, PSC: pyrethrum spray catches, LT/N Light trap associated with a person sleeping under a net), the village (Dielmo and Bandafassi) and the Anopheles species (An. funestus, An. gambiae and An. nili)

\begin{tabular}{|c|c|c|c|c|c|c|}
\hline \multirow[t]{2}{*}{ Species } & \multicolumn{3}{|c|}{ DIELMO } & \multicolumn{3}{|c|}{ BANDAFASSI } \\
\hline & HLC & PSC & LT/N & HLC & PSC & LT/N \\
\hline An. funestus & $20(2.96 \%)$ & $11(4.00 \%)$ & $28(2.85 \%)$ & $1(1.79 \%)$ & $0(0.00 \%)$ & $2(3.70 \%)$ \\
\hline An. gambiae & $6(2.74 \%)$ & $5(3.05 \%)$ & $5(2.96 \%)$ & $66(4.24 \%)$ & $21(5.37 \%)$ & $39(4.09 \%)$ \\
\hline An. nili & - & - & - & $8(3.59 \%)$ & $0(0.00 \%)$ & $0(0.00 \%)$ \\
\hline Total & 26 (2.91\%) & 16 (3.64\%) & $33(2.86 \%)$ & 75 (4.09\%) & 21 (4.79\%) & 41 (3.95\%) \\
\hline
\end{tabular}

significant correlation was observed for all species. The highest correlation coefficient was obtained for An. funestus (Spearmann rho $\left.^{2}=0.88, \mathrm{p}<0.0001\right)$. For An. gambiae, it was $0.74(\mathrm{p}<0.0001)$ and for Anopheles nili $0.64(\mathrm{p}=0.02)$. The parameters of the linear correlation wildly differed between species, confirming performance variations of each method according to the species.

\section{Discussion}

A large variety of traps have been developed for entomological studies, in order to avoid using human bait. According to the study, their relative efficiency, compared to HLC has been highly variable [14-18]. The aim of this study was to identify the best method to use for entomological studies in two Senegalese villages where malaria epidemiology is currently studied.

This work confirms that the method influences the quantity and the variety of mosquitoes collected. Among the three methods compared, all allowed to collect the principal known malaria vectors in studied areas:
An. gambiae s.l. and An. funestus in Dielmo [8], those two species as well as $A n$. nili in Bandafassi [9]. As previously reported [14], the variety of species collected with $\mathrm{LT} / \mathrm{N}$ was higher than that obtained with HLC and PSC in the two villages. This is probably due to the multiple attraction stimuli displayed by the method (light, odour...). As a consequence, LT/N would be the method to be used in biodiversity studies where a complete panel of Anopheles species is requested.

Significant differences in Anopheles density were observed according to the method used, with HLC being more performing than PSC and better than or equal to LT/N. Results obtained were different according to the vector species. On the other hand, they were similar in the two villages.

For An. gambiae s.l., HLC was the most efficient method probably because this species is highly anthropophilic and less influenced by light attraction [9]. Whereas studies performed in areas where HBR is very low (2-6 per person and per night) demonstrated no correlation between LT

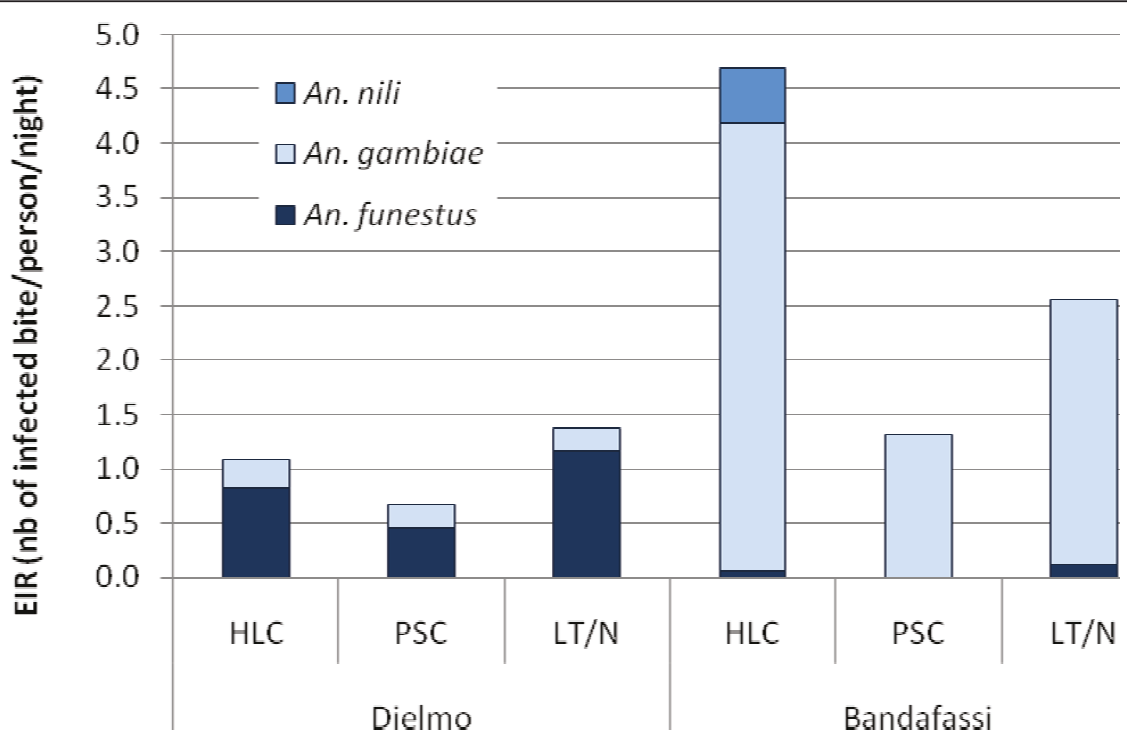

Figure 2 Entomological inoculation rate (EIR, number of infected bit/person/night) according to the method (HLC: human landing catches, PSC: pyrethrum spray catches, LT/N Light trap associated with a person sleeping under a net), the village (Dielmo and Bandafassi) and the Anopheles species (An. funestus, An. gambiae and An. nili). 


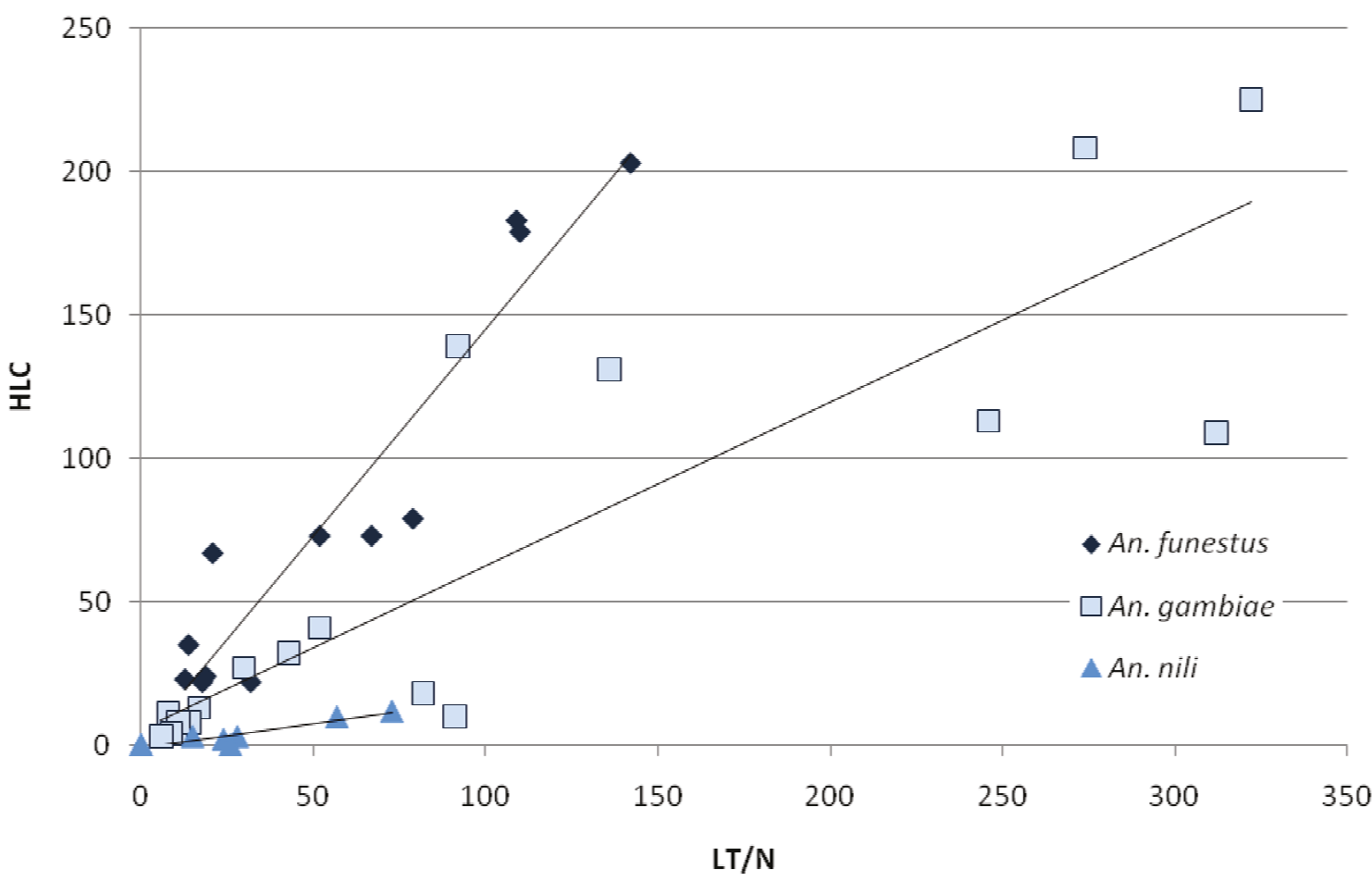

Figure 3 Correlation between mean number of Anopheles collected by light traps assocoated with a person sleeping under a net (LT/ $\mathrm{N})$ and by Human Landing Catches (HLC) for the 3 species: An. funestus, An. gambiae and An. nili.

and HLC $[15,16]$, various studies, performed in areas where Anopheles density is higher, report that LT display results that are proportional to those obtained with HLC [17-24]. This study confirmed a good correlation between the two methods for An. gambiae sampling $\left(\mathrm{r}^{2}=0.74\right)$ for an HBR (measured by HLC) ranging from 18 An. gambiae per person and per night in Dielmo to 194 in Bandafassi. In other studies, the relative efficiency of LT using HLC as a reference was highly variable among those reporting a good correlation. It was 1.7-1.9 in two of them [17,20], 1.2 in one [21] and only 0.7 in others $[18,19,24]$. In this work the efficiency ratio between LT/N and HLC was 0.6. In conclusion, to sample An. gambiae, although HLC is the reference method, $\mathrm{LT} / \mathrm{N}$ may be an alternative, only when density is sufficient.

For An. funestus, LT/N was the most efficient method in comparison to HLC and PSC. This is probably related to the high attraction exerted by light on this species, that is less anthropophilic than An. gambiae [25]. For $A n$. funestus, the correlation between results obtained by LT and HLC was good in some studies $[18,17,22,24]$ but not in another one where HBR was very low (0.04 An. funestus per person and per night) [15]. This study confirms a good correlation between the two methods for An. funestus HBR ranging from 7 bites per person and per night in Bandafassi to 56 in Dielmo. The relative efficiency of LT using HLC as a reference was highly variable among studies identifying a good correlation: 0.7 [24], 1.1 [18] 1.9 [17]. In this work it was 1.4. In conclusion, to sample $A n$. funestus, LT/N seems to be a good alternative to HLC especially when density is sufficient.

In this study, the mean anopheles density was lower with PSC for all species. This collecting technique is often used in entomological studies to catch fed indoor-resting females. It cannot be considered as a quantitative method to determine aggressive anopheles density. Indeed, it tends to miss the mosquitoes that leave the house after feeding and includes those entering the house after feeding outdoor [26]. Moreover, this technique is not standardized (different insecticide may be used, time when collection is performed differs, dispersion of specimens is possible if holes are present in the walls...). In areas where an important resistance to insecticide is detected, it is possible that a part of mosquitoes present in the room will not be collected by PSC.

In this study, no influence of the method used was detected on the infection rates measured. Contradictory results have been reported concerning this parameter. In some previous studies, CSP rates were not significantly different when estimated by HLC and LT/N [17,27]. In others it was twice higher in LT than in HLC [16,21], probably because light traps tended to attract and capture resting mosquitoes that have a higher sporozoite rate than host-seeking ones [26]. In this study, since infection 
rates were similar among methods and species, EIR variations followed the anopheles density. In Dielmo, where An. funestus was the principal vector, $\mathrm{LT} / \mathrm{N}$ was the method that reported the higher EIR. On the other hand, in Bandafassi where An. gambiae s.l. was the main vector, EIR calculated with HLC was higher.

\section{Conclusions}

In order to have at disposal reliable entomological data, it is important to choose carefully the method used to collect mosquitoes according to the study area and, more specifically, according to vector species responsible for transmission. No method seems as reliable as HLC for measuring malaria transmission. It is possible, but difficult, to directly extrapolate the results obtained by a method to another one since coefficients vary according to species. In the studied areas, our work clearly demonstrates a good correlation between HLC and LT/N for Anopheles densities and CSP rates. In the future, if HLC have to be stopped, for ethical reasons, the study of malaria transmission in these areas could be performed by using light traps associated with a person sleeping under a net.

\section{Acknowledgements}

The authors thank K. Bandia and R. Keita for helpful technical assistance during the study.

This study was funded by a grand of MTIMBA (Malaria Transmission Intensity and Mortality Burden Across Africa) and by IRD (Institut de Recherche pour le Développement).

\section{Author details}

${ }^{1}$ Institut de Recherche pour le Développement, UMR 198 URMITE Campus international de Hann, IRD BP 1386 CP 18524 Dakar, Sénégal. ²Université Cheikh Anta Diop de Dakar, Département de Biologie Animale, BP 5005 Dakar, Sénégal.

\section{Authors' contributions}

CS and JFT equally contributed to the design and the conception of study and provided the scientific supervision. MON, AG and CB conducted field activities and molecular biology study. MON and CM analysed data and drafted the manuscript. LK and OF contributed to the analysis and interpretation of data. All authors read and approved the final manuscript.

\section{Conflicts of interests}

The authors declare that they have no competing interests.

Received: 11 July 2011 Accepted: 19 September 2011 Published: 19 September 2011

\section{References}

1. WHO: Entomological field techniques for malaria control: Part 1. Learner's guide. 1992

2. Le Goff G, Carnevale P, Roberts V: Comparison of catches by landings on humans and by CDC light traps for sampling of mosquitoes and evaluation of malaria transmission in South Cameroon. Ann Soc Belg Med Trop 1993, 73:55-60.

3. Odetoyinbo JA: Preliminary investigation on the use of a light-trap for sampling malaria vectors in the Gambia. Bull World Health Organ 1969 40:547-560.

4. Anderson JR, Linhares AX: Comparison of several different trapping methods for Culicoides variipennis (Diptera: Ceratopogonidae). J Am Mosa Control Assoc 1989, 5:325-334
5. Costantini C, Sagnon NF, della TA, Diallo M, Brady J, Gibson G, Coluzzi M: Odor-mediated host preferences of West African mosquitoes, with particular reference to malaria vectors. Am J Trop Med Hyg 1998, 58:56-63.

6. Mathenge EM, Killeen GF, Oulo DO, Irungu LW, Ndegwa PN, Knols BGJ: Development of an exposure-free bednet trap for sampling Afrotropical malaria vectors. Med Vet Entomol 2002, 16:67-74.

7. Carnevale P, Lepont F: Epidemiologie du paludisme humain en République Populaire du Congo: Utilisation des pièges lumineux " $C D C^{\prime}$ comme moyen d'échantillonnage des populations anophéliennes. Cah ORSTOM Sér Ent Méd Par 1973, 10:273-283.

8. Fontenille D, Lochouarn L, Diagne N, Sokhna C, Lemasson JJ, Diatta M, Konate L, Faye F, Rogier C, Trape JF: High annual and seasonal variations in malaria transmission by anophelines and vector species composition in Dielmo, a holoendemic area in Senegal. Am J Trop Med Hyg 1997, 56:247-253.

9. Fontenille D, Lochouarn L, Diatta M, Sokhna C, Dia I, Diagne N, Lemasson JJ, Ba K, Tall A, Rogier C, Trape JF: Four years' entomological study of the transmission of seasonal malaria in Senegal and the bionomics of Anopheles gambiae and A. arabiensis. Trans $R$ Soc Trop Med Hyg 1997, 91:647-652.

10. Trape JF, Rogier C, Konate L, Diagne N, Bouganali H, Canque B, Legros F, Badji A, Ndiaye G, Ndiaye P, Brahimi K, Faye O, Druilhe P, Dasilva LP: The Dielmo project - A longitudinal-study of natural malaria infection and the mechanisms of protective immunity in a community living in a holoendemic area of Senegal. Am J Trop Med Hyg 1994, 51:123-137.

11. Trape JF, Pison G, Preziosi MP, Enel C, du Lou AD, Delaunay V, Samb B, Lagarde $\mathrm{E}$, Molez JF, Simondon F: Impact of chloroquine resistance on malaria mortality. C R Acad Sci III 1998, 321:689-697.

12. Gillies MT, Meillon B: The Anophelinae of Africa South of the Sahara (Ethiopian zoogeographical region)., 2 1968, 343.

13. Wirtz RA, Duncan JF, Njelesani EK, Schneider I, Brown AE, Oster CN, Were JBO, Webster HK: ELISA method for detecting Plasmodium falciparum circumsporozoite antibody. Bull World Health Organ 67:535-542.

14. Sadanandane C, Jambulingam P, Subramanian S: Role of modified CDC miniature light-traps as an alternative method for sampling adult anophelines (Diptera: Culicidae) in the National Mosquito Surveillance Programme in India. Bull Entomol Res 2004, 94:55-63.

15. Govella NJ, Chaki PP, Mpangile JM, Killeen GF: Monitoring mosquitoes in urban Dar es Salaam: Evaluation of resting boxes, window exit traps, CDC light traps, Ifakara tent traps and human landing catches. Parasit Vectors 2011, 4:40

16. Mbogo CNM, Glass GE, Forster D, Kabiru EW, Githure Jl, Ouma JH, Beier JC: Evaluation of light traps for sampling Anopheline mosquitos in Kilifi, Kenya. J Am Mosq Control Assoc 1993, 9:260-263.

17. Mathenge EM, Omweri GO, Irungu LW, Ndegwa PN, Walczak E, Smith TA Killeen GF, Knols BGJ: Comparative field evaluation of the Mbita trap, the Centers for Disease Control light trap, and the human landing catch for sampling of malaria vectors in western Kenya. Am J Trop Med Hyg 2004, 70:33-37.

18. Mathenge EM, Misiani GO, Oulo DO, Irungu LW, Ndegwa PN, Smith TA, Killeen GF, Knols BGJ: Comparative performance of the Mbita trap, CDC light trap and the human landing catch in the sampling of Anopheles arabiensis, An. funestus and culicine species in a rice irrigation in western Kenya. Malar J 2005, 4:7

19. Magbity EB, Lines JD, Marbiah MT, David K, Peterson E: How reliable are light traps in estimating biting rates of adult Anopheles gambiae s.l. (Diptera: Culicidae) in the presence of treated bed nets? Bull Entomol Res 2002, 92:71-76

20. Fornadel CM, Norris LC, Norris DE: Centers for Disease Control light traps for monitoring Anopheles arabiensis human biting rates in an area with low vector density and high insecticide-treated bed net use. Am J Trop Med Hyg 2010, 83:838-842.

21. Davis JR, Hall T, Chee EM, Majala A, Minjas J, Shiff CJ: Comparison of sampling anopheline mosquitos by light-trap and human-bait collections indoors at Bagamoyo, Tanzania. Med Vet Entomol 1995, 9:249-255

22. Githeko AK, Service MW, Mbogo CM, Atieli FA, Juma FO: Sampling Anopheles arabiensis, A. gambiae sensu-lato and A. funestus (Diptera, Culicidae) with CDC light-traps near a rice irrigation area and a sugarcane belt in Western Kenya. Bull Entomol Res 1994, 84:319-324. 
23. Costantini C, Sagnon NF, Sanogo E, Merzagora L, Coluzzi M: Relationship to human biting collections and influence of light and bednet in CDC light-trap catches of West African malaria vectors. Bull Entomol Res 1998 88:503-511.

24. Lines JD, Curtis CF, Wilkes TJ, Njunwa KJ: Monitoring human-biting mosquitoes (Diptera, Culicidae) in Tanzania with light-traps hung beside mosquito nets. Bull Entomol Res 1991, 81:77-84.

25. Dia I, Konate L, Samb B, Sarr JB, Diop A, Rogerie F, Faye M, Riveau G, Remoue F, Diallo M, Fontenille D: Bionomics of malaria vectors and relationship with malaria transmission and epidemiology in three physiographic zones in the Senegal River Basin. Acta Trop 2008, 105:145-153.

26. Mboera LE: Sampling techniques for adult Afrotropical malaria vectors and their reliability in the estimation of entomological inoculation rate. Tanzan Health Res Bull 2005, 7:117-124.

27. Faye O, Diallo S, Gaye O, Ndir O, Faye O: [Comparative efficacy of the use of cdc light traps and humans to sample Anopheles populations results obtained in the Bignona zone of Senegal](in French). Bull Soc Path Exot 1992, 85:185-189.

doi:10.1186/1475-2875-10-270

Cite this article as: Ndiath et al: Methods to collect Anopheles

mosquitoes and evaluate malaria transmission: A comparative study in

two villages in Senegal. Malaria Journal 2011 10:270.

\section{Submit your next manuscript to BioMed Central} and take full advantage of:

- Convenient online submission

- Thorough peer review

- No space constraints or color figure charges

- Immediate publication on acceptance

- Inclusion in PubMed, CAS, Scopus and Google Scholar

- Research which is freely available for redistribution

Submit your manuscript at www.biomedcentral.com/submit 